Revista Destaques Acadêmicos, Lajeado, v. 9, n. 3, 2017. ISSN 2176-3070

DOI: http://dx.doi.org/10.22410/issn.2176-3070.v9i3a2017.1535

www.univates.br/revistas

\title{
VARIAÇÕES NO MICROCLIMA E CARACTERÍSTICAS DO SOLO EM PAISAGENS COM DIFERENTES COBERTURAS VEGETAIS: AÇÃO DE CAMPO JUNTO AO MORRO DA HARMONIA - TEUTÔNIA/RS
}

\author{
Melissa Heberle ${ }^{1}$, Berenice Maria Dalla Costa da Silva ${ }^{2}$, \\ Charlyan de Souza Lima ${ }^{3}$, Renato Santiago Quintal ${ }^{4}$, Claudete Rempel $^{5}$, \\ Marina Schmidt Dalzochio ${ }^{6}$
}

Resumo: A influência da cobertura vegetal sobre o clima acontece de diferentes formas,
interferindo tanto na entrada de luz e umidade relativa quanto nas variações de
temperatura. A maior parte das florestas existentes é grande emissora de umidade por
intermédio de um processo chamado de evapotranspiração. Faz-se necessário apontar
que a cobertura vegetal igualmente protege os solos. Objetivou-se comparar as variações
microclimáticas e as características do solo em duas áreas com diferentes coberturas
vegetais. A área de estudo foi a localidade do Morro da Harmonia - Teutônia - RS,
que se encontra localizada em uma área de 120 hectares em uma região com vegetação

1 Licenciada e mestre em Letras, doutoranda do Programa de Pós-Graduação em Ambiente e Desenvolvimento da Univates, professora do IFSul. melissaheberle@ifsul.edu.br

2 Graduada em Pedagogia e em Administração Pública, especialista em Educação e Diversidade e em Psicopedagogia Clínica e Educacional, professora da rede municipal de Juara-MT e professora interina da UNEMAT.

3 Licenciado em Ciências com Habilitação em Biologia, zootecnista e mestre em Ciência Animal, doutorando do Programa de Pós-Graduação em Ambiente e Desenvolvimento da Univates, professor de Biologia da SEDUC-MA e professor substituto da UFMA. charlyansl@yahoo.com.br

4 Bacharel em Administração e Ciências Navais, mestre em Ciências Contábeis e doutorando do Programa de Pós-Graduação em Ambiente e Desenvolvimento da Univates. Trabalha no Departamento de Sistemas de Pagamento da Pagadoria de Pessoal da Marinha. rsantiago79@hotmail.com

5 Bióloga, doutora em Ecologia, professora do Programa de Pós-Graduação em Ambiente e Desenvolvimento da Univates. crempel@univates.br

6 Bióloga, doutora em Biologia, bolsista de Pós-Doutorado do Programa de Pós-Graduação em Ambiente e Desenvolvimento da Univates. mahsdalzochio@gmail.com 
majoritariamente composta por remanescentes das Florestas Estacional Decidual e Ombrófila Mista. Foram verificadas e comparadas as variáveis microclimáticas (temperatura, umidade relativa do ar e entrada de luz) e do solo (presença e altura da serapilheira, umidade, $\mathrm{pH}$, cor e compactação do solo) entre duas áreas com coberturas vegetais diferentes: uma área florestada e outra de campo aberto. Os resultados apontaram que as áreas cobertas com florestas preservam o solo e o clima. Por outro lado, a falta de vegetação contribui para tornar o solo mais compacto. Conclui-se que o desmatamento e a degradação florestal ocasionam a mudança de clima, ameaçam a fauna e a flora ao destruir seu habitat, comprometem rios e bacias hídricas e favorecem o enfraquecimento do solo e a ocorrência de erosão.

Palavras-chave: Área florestada. Campo aberto. Serapilheira. Proteção do solo.

\section{INTRODUÇÃO}

A influência da cobertura vegetal sobre o clima acontece de diferentes formas, influenciando tanto na entrada de luz e umidade relativa quanto nas variações de temperatura. Isso significa que alterar ou destruir a vegetação de uma determinada área é também propiciar alterações climáticas neste local (COLTRI, 2006; ABREU, 2008).

As formações vegetais possuem a função de absorver parte da energia solar que incide sobre a superfície terrestre. Dessa forma, quando o grau de reflexão aumenta, maior tende a ser o impacto do efeito estufa, pois haverá mais radiação disseminando-se e retornando para a atmosfera (TEXEIRA, LUCAS, 2014). Nesse contexto, áreas mais abertas, com menor presença de vegetação, tendem a absorver mais calor, provocando o aumento de temperatura.

A presença de cobertura vegetal igualmente influencia a quantidade de umidade presente no ar. As florestas existentes são grandes emissoras de umidade através de um processo chamado de evapotranspiração. A consequência de uma maior umidade do ar é a menor amplitude térmica (a diferença entre a maior e a menor temperatura), ou seja, a ocorrência de médias de temperaturas mais constantes. Isso ocorre em razão do calor específico da água, responsável por conservar o calor por mais tempo (YU, HIEN, 2006; AYOADE, 2011).

A cobertura vegetal similarmente protege os solos. A erosão dos solos se verifica quando a água das chuvas provoca a remoção de partículas que formam o solo, quando esse é protegido pela cobertura vegetal que reduz a energia das gotas, fazendo com que elas não tenham força para retirar partículas (SOUTO, 2006). A exposição direta aos raios solares e ao impacto das gotas de chuva promove a desestruturação e a desagregação do solo, resultando em erosão. Por essa razão, a cobertura vegetal tem sua importância para a manutenção da umidade do solo e para o favorecimento da decomposição da parte aérea e do sistema radicular das plantas, pois as partículas decompostas agregam-se mais facilmente, favorecendo o aumento de matéria orgânica e de nutrientes disponíveis ao solo (SANTANA, 2005). 
Em face do exposto, o objetivo da pesquisa foi comparar as variações microclimáticas e as características do solo em duas áreas com diferentes coberturas vegetais, em um remanescente de Florestas Estacional Decidual e Ombrófila Mista com Araucária do Morro da Harmonia - Teutônia - RS.

\section{MATERIAIS E MÉTODOS}

\subsection{Local de estudo}

A área de estudo encontra-se situada na região do Vale do Taquari, correspondendo à Unidade Geomorfológica Patamares da Serra Geral, região fisiográfica da Depressão Central, manifestando relevo identificado como sendo suave ondulado sob a forma de colinas e vales fluviais, relacionados à ocorrência de morros testemunhos dispersos, bem como à presença de cristas simétricas, com altitudes variando entre 250 e 700 metros acima do nível do mar. A região do Vale do Taquari é uma das 28 regiões do Rio Grande do Sul, distando cerca de $120 \mathrm{~km}$ da capital do estado. É banhada pelo Rio Taquari e seus afluentes, que foram importantes para a ocupação do território de grupos sociais como os indígenas e europeus (WEBER, 2016).

É em Teutônia que se situa o Morro da Harmonia, unidade de análise da presente pesquisa. Segundo informações publicadas pela prefeitura (Teutônia, 2012 apud SCHUHMANN, 2012), o município é um dos 497 municípios do Rio Grande do Sul, localizando-se no interior do estado, na região do Vale do Taquari. Sua área é de $179,2 \mathrm{Km}^{2}$, com altitude média de $83 \mathrm{~m}$, sendo que o Morro da Harmonia é o ponto mais alto, com $600 \mathrm{~m}$.

A localidade do Morro da Harmonia encontra-se localizada em uma área de 120 hectares, em uma região com vegetação majoritariamente composta por remanescentes de Florestas Estacional Decidual e Ombrófila Mista com Araucária. O clima é categorizado como superúmido mesotérmico, temperado, sem período seco, com temperatura média anual variando em torno de $18^{\circ} \mathrm{C} \mathrm{e}$ precipitação média anual entre 1400 e $1600 \mathrm{~mm}$. O solo da região é constituído por Terra Roxa Estruturada Eutrófica + Terra Roxa Estruturada Latossólica Distrófica, tendo como substrato o basalto da Formação Serra Geral do período Jurocretáceo (WINDISCH, STEFFENS, 2007).

Aárea em estudo, o Morro da Harmonia, constitui uma reserva particular, sendo que a vegetação florestal em parte significativa corresponde a formações em regeneração após corte seletivo. Distintas formações secundárias em diferentes estágios de sucessão podem ser observadas, notadamente nas áreas periféricas. Em função da crescente expansão agrícola e de ações antrópicas, a vegetação original vem sendo substituída por uma mata secundária como, por exemplo, capoeiras em diversos estágios e culturas diversificadas em pequenas propriedades como, policultura, incluindo cultivos anuais e perenes, pecuária e reflorestamento (WINDISCH, STEFFENS, 2007, p. 376). 


\subsection{Coleta de dados}

Neste estudo foram verificadas e comparadas as variáveis microclimáticas e do solo entre duas áreas com coberturas vegetais diferentes: uma área florestada (Figura 1 - 29 $16^{\prime} 42.4^{\prime \prime}$ N51 52' 07.3" W, altitude 511m) e outra de campo aberto (Figura 2 - 29 $9^{\circ} 16^{\prime} 42.0^{\prime \prime} \mathrm{N} ; 51^{\circ} 52^{\prime}$ 07.0" W, altitude 419m), no dia 22 de julho de 2017. Para as variáveis microclimáticas foram aferidas: temperatura, umidade relativa do ar e entrada de luz. Para as características do solo foram coletadas: presença e altura da serapilheira, umidade, $\mathrm{pH}$, cor e compactação do solo. Para cada área com cobertura vegetal diferente foram feitos 4 pontos amostrais.

Figura 1. Imagens da vegetação superior aos pontos de área florestada: A - ponto 01; $\mathrm{B}$ - ponto 02 ; C - ponto 03 ; D - ponto 04

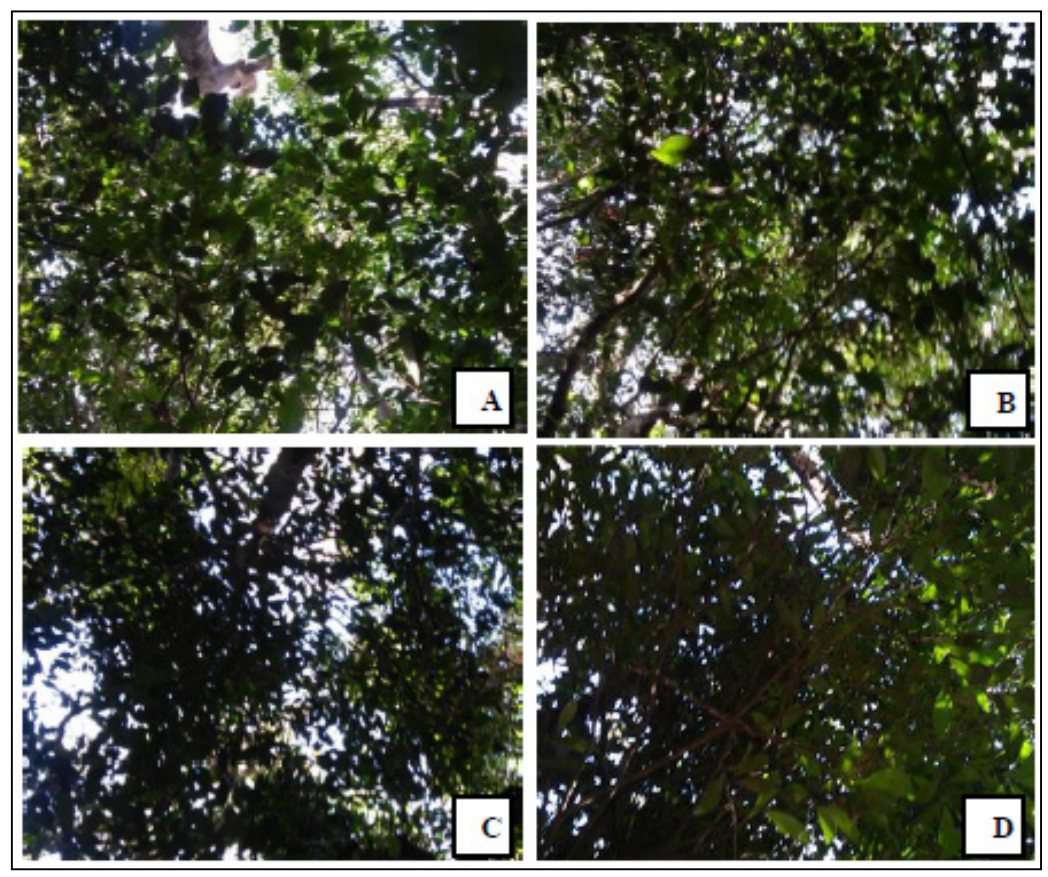


Figura 2. Área de vegetação aberta

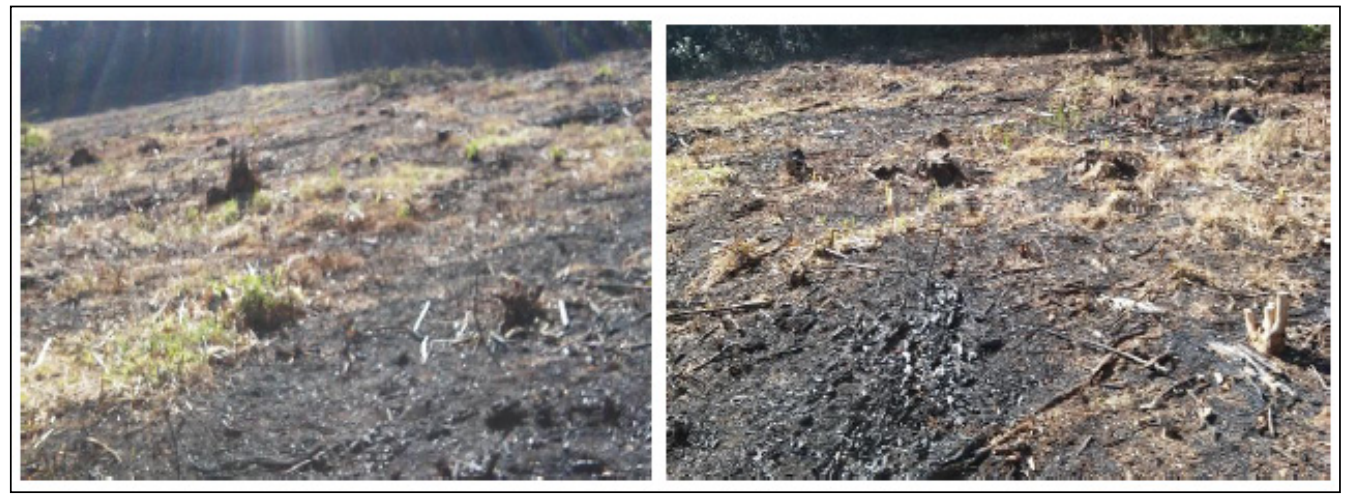

A temperatura e umidade relativa do ar foram aferidas utilizando um termohigrômetro digital (Figura 3a). A entrada de luz foi verificada com sonda analógica de lumens. A umidade e o $\mathrm{pH}$ do solo também foram coletados com sonda analógica inserida diretamente no solo com auxílio de dois eletrodos (Figura 3b).

Figura 3. Aparelhos utilizados na coleta de dados: A - termohigrômetro; B e C - medidor de solo 3x1 ( $\mathrm{pH}$, umidade e luz).

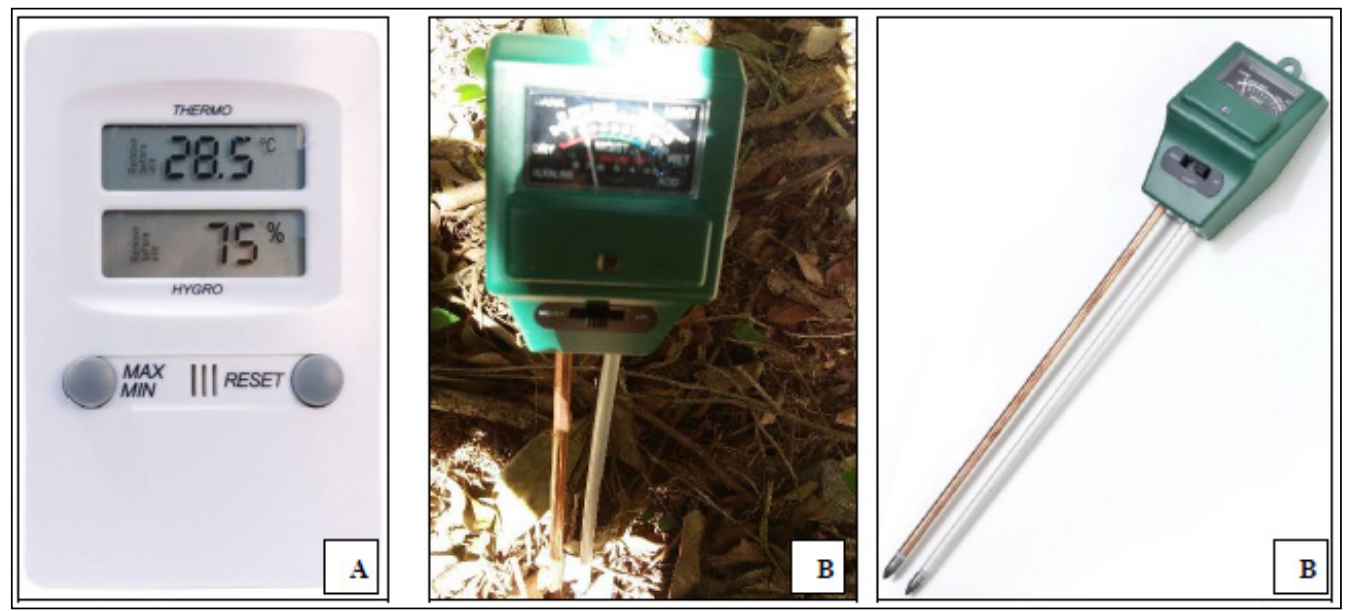

A presença e a altura da serapilheira foram determinadas com auxílio de um palito grande de bambu equipado com haste de metal móvel que se deslocava até a superfície da serapilheira. Após a marcação, a altura foi determinada com auxílio de uma régua em centímetros (Figura 4). 
Figura 4. Coleta da altura da serapilheira.

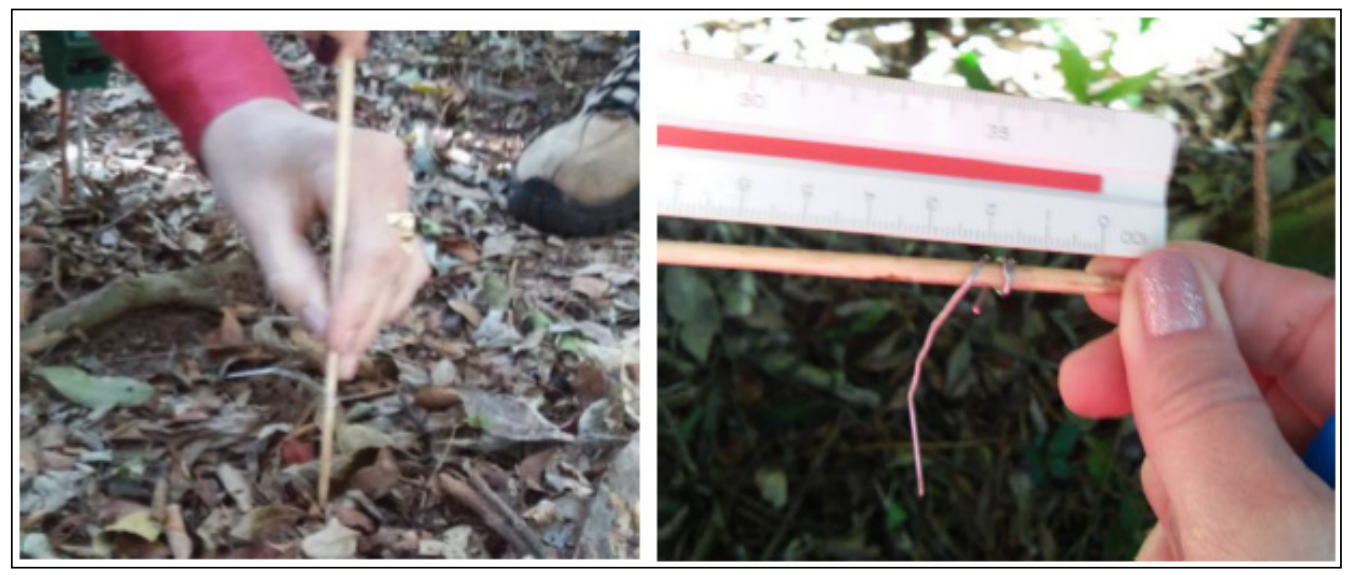

A cor foi determinada com auxílio da paleta de cores da Carta de Munsell (MUNSELL COLOR, 2000), cujas cores representam parâmetros morfológicos para a classificação do Sistema Brasileiro de Classificação de Solos, e a compactação do solo especificada por meio do "teste da cobrinha". Esse teste consiste em umedecer uma amostra de solo, manipular bastante essa massa entre os dedos e tentar moldar com ela uma "cobrinha", a saber: "cobrinha" dobrada e sem rachaduras (textura argilosa); "cobrinha" quebrada ou com rachaduras ao ser dobrada (textura média); impossibilidade de formação da "cobrinha" (textura arenosa).

Após a coleta, os dados foram tabulados e foram calculados em planilha Excel a média e o desvio padrão para cada área. Gráficos de barras foram elaborados para facilitar a visualização e discussão dos resultados.

\section{RESULTADOS E DISCUSSÃO}

\subsection{Variáveis microclimáticas}

Na tabela 1 são apresentados os dados microclimáticos coletados na área florestada e na área de campo aberto no Morro da Harmonia. 
Tabela 1 - Variáveis microclimáticas

\begin{tabular}{ccccccc}
\hline \multirow{2}{*}{ AMOsTRAS } & \multicolumn{2}{c}{$\begin{array}{c}\text { TEMPERATURA DO } \\
\text { AR }\left({ }^{\circ} \mathbf{C}\right)\end{array}$} & \multicolumn{2}{c}{ UMIDADE DO AR (\%) } & \multicolumn{2}{c}{$\begin{array}{c}\text { ENTRADA DE LUZ } \\
\text { SOLAR }\end{array}$} \\
\cline { 2 - 7 } & $\begin{array}{c}\text { Área } \\
\text { Florestada }\end{array}$ & $\begin{array}{c}\text { Campo } \\
\text { Aberto }\end{array}$ & $\begin{array}{c}\text { Área } \\
\text { Florestada }\end{array}$ & $\begin{array}{c}\text { Campo } \\
\text { Aberto }\end{array}$ & $\begin{array}{c}\text { Área } \\
\text { Florestada }\end{array}$ & $\begin{array}{c}\text { Campo } \\
\text { Aberto }\end{array}$ \\
\hline 01 & 17.6 & 20.3 & 73 & 47 & 200 & 900 \\
\hline 02 & 18.2 & 24.6 & 58 & 42 & 450 & 2,000 \\
\hline 03 & 18.1 & 27.4 & 60 & 33 & 2,000 & 2,000 \\
\hline 04 & 20.1 & 30.5 & 25 & 29 & 50 & 2,000 \\
\hline Média & 18.5 & 25.7 & 54 & 37.75 & 675 & 1725 \\
\hline Desvio Padrão & 1.098 & 4.33 & 20.44 & 8.22 & 898.61 & 550 \\
\hline
\end{tabular}

Fonte: Dados da pesquisa (2017).

A temperatura média do ar nas áreas com cobertura vegetal foi de $18.5^{\circ} \mathrm{C}$, enquanto que na área de campo aberto foi de $25.7^{\circ} \mathrm{C}$. A umidade relativa média nas amostras com cobertura vegetal foi de $54 \%$, enquanto na área de campo aberto foi de $37,7 \%$. Por fim, a entrada de luz nas áreas com floresta foi em média 625 lumens, enquanto na área de campo aberto foi de 1750 lumens. Nossos resultados comprovam que a influência da cobertura vegetal sobre o clima influencia tanto na entrada de luz e umidade relativa quanto nas variações de temperatura. Isso se justifica em razão da temperatura do ar que influencia nas camadas do solo, e o movimento contínuo de calor entre o solo com vegetação e o ar, que é menor do que no solo exposto (sem cobertura) (PEREIRA; ANGELOCCI; SENTELHAS, 2002).

A pesquisa de Natel Junior (2015) corroborou a ideia da influência da cobertura vegetal no comportamento térmico e na capacidade de atenuação das temperaturas. Isso significa que alterar ou destruir a vegetação de um dado local é também propiciar alterações climáticas neste local. Assim, os ambientes com maior concentração de vegetação apresentam maior capacidade de evapotranspiração, pois são eficientes em reter elevada quantidade de água, sendo considerada uma das principais razões do efeito atenuante em áreas verdes. No entanto, quando se tem áreas com vegetação escassa, a interação entre o ar e o solo ocorre diretamente, pois a radiação solar que incide será maior do que em áreas com vegetação fechada (TEXEIRA, LUCAS, 2014).

As formações vegetais possuem a importante função de absorver parte da energia solar que incide sobre a superfície terrestre. Assim, quando o grau de reflexão é maior, maior tende a ser o impacto do efeito estufa, pois haverá mais radiação disseminando-se e retornando para a atmosfera. Dessa forma, áreas mais abertas, com menor presença de vegetação, tendem a absorver mais calor, provocando o aumento das temperaturas. A presença de uma maior cobertura vegetal também influencia a quantidade de umidade presente no ar. A maior parte das florestas existentes é grande emissora de umidade através de um processo chamado de evapotranspiração. A consequência de uma maior 
umidade do ar é a menor amplitude térmica (a diferença entre a maior e a menor temperatura), ou seja, a ocorrência de médias de temperaturas mais constantes. Isso ocorre em razão do calor específico da água, responsável por conservar o calor por mais tempo. Estudo empreendido por Correia et al. (2007) na região amazônica chamou a atenção para o fato de que mudanças na cobertura vegetal decorrentes de desflorestamentos podem levar à diminuição da evapotranspiração, modificando o balanço de água, produzindo consequências naquela região e sua vizinhança.

\subsection{Características do solo}

Nas tabelas 2 e 3 são apresentados os dados das características do solo na área florestada e na área de campo aberto no Morro da Harmonia.

Tabela 2. Características do solo: serapilheira, umidade e pH

\begin{tabular}{|c|c|c|c|c|c|c|}
\hline \multirow{2}{*}{ AMOSTRAS } & \multicolumn{2}{|c|}{$\begin{array}{c}\text { ALTURA DA } \\
\text { SERAPILHEIRA }(\mathrm{cm})\end{array}$} & \multicolumn{2}{|c|}{ UMIDADE DO SOLO (\%) } & \multicolumn{2}{|c|}{ pH DO SOLO } \\
\hline & $\begin{array}{c}\text { Área } \\
\text { Florestada }\end{array}$ & $\begin{array}{l}\text { Campo } \\
\text { Aberto }\end{array}$ & $\begin{array}{c}\text { Área } \\
\text { Florestada }\end{array}$ & $\begin{array}{l}\text { Campo } \\
\text { Aberto }\end{array}$ & $\begin{array}{c}\text { Área } \\
\text { Florestada }\end{array}$ & $\begin{array}{l}\text { Campo } \\
\text { Aberto }\end{array}$ \\
\hline 01 & 2 & 0 & 10 & 60 & 6.5 & 7 \\
\hline 02 & 1.7 & 0 & 10 & 20 & 6.5 & 7 \\
\hline 03 & 1.6 & 0 & 10 & 15 & 7.5 & 8 \\
\hline 04 & 5.3 & 0 & 25 & 25 & 8 & 7.5 \\
\hline Média & 2.65 & 0 & 13.75 & 30 & 7.125 & 7.375 \\
\hline Desvio Padrão & 1.77 & 0 & 7.5 & 20.41 & 0.75 & 0.4787 \\
\hline
\end{tabular}

Fonte: Dados da pesquisa (2017).

Tabela 3. Características do solo: textura e cor

\begin{tabular}{ccccc}
\hline \multirow{2}{*}{ AMOSTRAS } & \multicolumn{2}{c}{ TEXTURA DO SOLO } & \multicolumn{2}{c}{ COR DO SOLO } \\
\cline { 2 - 5 } & Área Florestada & Campo Aberto & Área Florestada & Campo Aberto \\
\hline 01 & Média & Argiloso & Castanho & Castanho \\
\hline 02 & Média & Argiloso & Castanho & Castanho \\
\hline 03 & Média & Argiloso & Castanho & Castanho \\
\hline 04 & + Argiloso & $\begin{array}{c}\text { Média }+\mathrm{p} / \\
\text { Argiloso }\end{array}$ & Castanho & Castanho \\
\hline Média & Média & Argiloso & Castanho & Castanho \\
\hline
\end{tabular}

Fonte: Dados da pesquisa (2017).

A umidade média do solo na área com cobertura vegetal foi de 13,75\% enquanto nas áreas de campo aberto esta chegou a 30\%. Em relação à umidade do solo, acredita-se que seja maior nas áreas abertas devido ao contato direto da superfície do solo com o orvalho da manhã. O dia da coleta dos dados precedeu 
a dias bastante frios e úmidos. Já o $\mathrm{pH}$ médio nas áreas de floresta foi de 7,1 enquanto nas áreas abertas foi de 7,3. A textura do solo com cobertura florestal foi média, indicando baixo nível de compactação, enquanto da área aberta foi argiloso, indicando alto índice de compactação (Figuras 5 e 6). O solo das duas áreas apresentou cor castanha, indicando elevados índices de matéria orgânica. Sendo assim, solos com superfície desprotegida são mais suscetíveis aos efeitos do clima, sofrendo grandes oscilações e afetando a biota do solo, que o fertiliza.

Figura 5. Aspecto final da amostra de solo com base no teste da "cobrinha" em área florestada: $\mathrm{A}$ - ponto 01 ; $\mathrm{B}$ - ponto 02 ; $\mathrm{C}$ - ponto 03 ; $\mathrm{D}$ - ponto 04

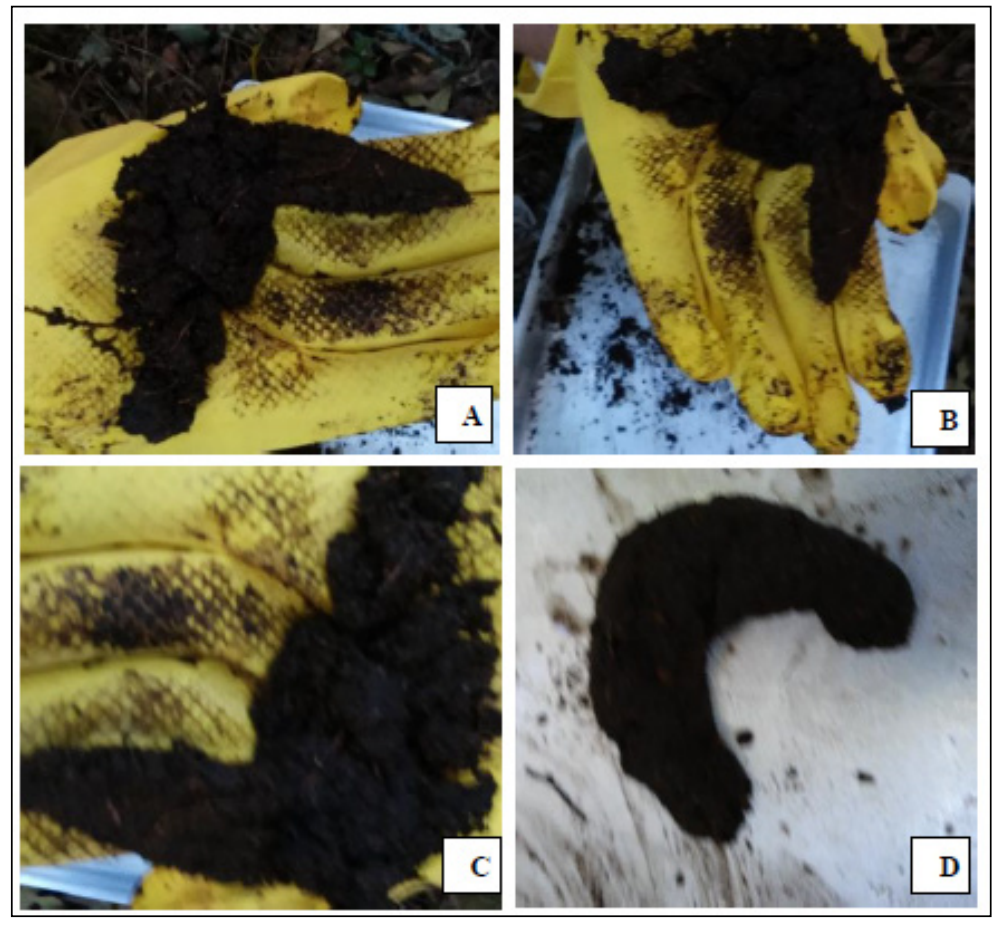


Figura 6. Aspecto final da amostra de solo com base no teste da "cobrinha" em área de campo aberto: $\mathrm{A}$ - ponto $01 ; \mathrm{B}$ - ponto $02 ; \mathrm{C}$ - ponto 03 ; $\mathrm{D}$ - ponto 04

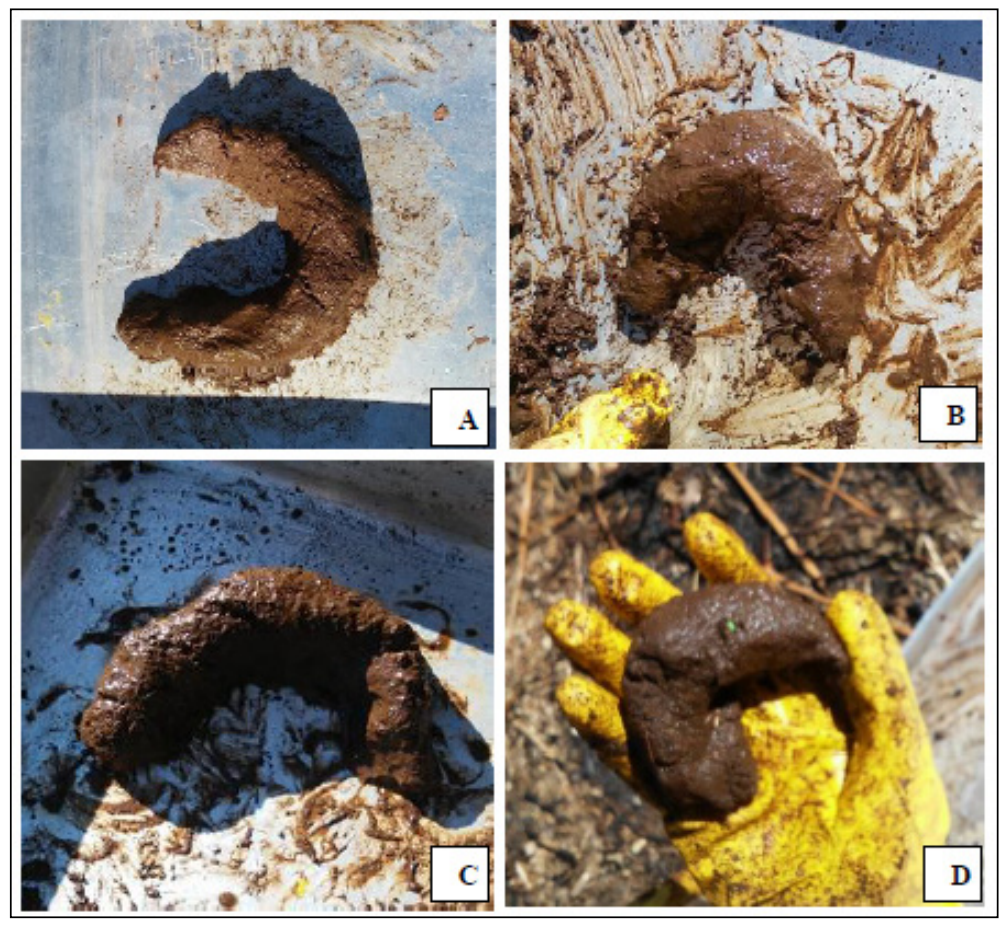

A compactação prejudica ainda mais já que a capacidade de infiltração pode ser reduzida drasticamente, prejudicando o abastecimento dos lençóis freáticos e gerando graves problemas para população humana, como as enchentes. Usualmente, a capacidade de infiltração de solos com florestas é elevada, o que é responsável por pequena quantidade de escoamento superficial (PRITCHETT, 1979 apud TUCCI, CLARKE, 1997, p. 137). A baixa capacidade de infiltração dos solos resulta em maior escoamento superficial, levando a enchentes, inundações e erosão (TUCCI, CLARKE, 1997, p. 138). A erosão dos solos acontece quando a água das chuvas provoca a remoção de partículas que formam o solo e, quando esse solo é protegido pela cobertura vegetal, essa última reduz a energia das gotas, fazendo com que elas não tenham força para retirar partículas.

Nas áreas analisadas, verificou-se ausência de serapilheira em campo aberto. A cobertura vegetal também protege os solos, assim, a serapilheira é importante por dar vida biológica ao solo, contribuir para absorção maior das aguas da chuva e protegê-lo das erosões, pois pode atuar como uma "barreira", evitando a lixiviação causada pelas chuvas, além de reter quantidades expressivas de água que diminuem a evaporação do solo. O solo mais argiloso, devido as suas propriedades pedológicas, tende a ocasionar mais enchentes, 
principalmente quando não possui quantidade expressiva de serapilheira em sua região superficial. A serapilheira atua no processo de transferência de matéria orgânica e de nutrientes essenciais da vegetação para o solo, também tem a capacidade de armazenar sementes em estado de dormência ou prontas para a germinação, além de fornecer abrigo para a fauna invertebrada que participa da decomposição dos materiais que compõem a serapilheira, estes consequentemente melhoram a fertilidade natural do solo (COSTA et al., 2007; VITAL et al., 2004).

\section{CONCLUSÕES}

Conforme apresentado na introdução, o objetivo da pesquisa foi comparar as variações microclimáticas em duas áreas com diferentes coberturas vegetais, bem como as variações das características do solo em duas áreas com diferentes coberturas vegetais.

Este estudo contribui para um melhor entendimento sobre como a falta de cobertura vegetal influencia o clima local e pode gerar alguns graves problemas à biodiversidade e a população humana. Áreas cobertas com florestas preservam o solo e o clima, conservando assim a biodiversidade do solo. A biota do solo é importante em uma série de processos que garantem o funcionamento dos ecossistemas, como a ciclagem de nutrientes, já a falta de vegetação, por outro lado, deixa o solo desprotegido e susceptível às bruscas oscilações do clima, características da região de estudo. Além do mais, o solo sem cobertura torna-se mais compacto, aumentando o escoamento superficial da água da chuva, levando a enchentes e erosão do solo.

Assim, o desmatamento e a degradação florestal causam a mudança de clima, alteram os processos de ciclagem de nutrientes, ameaçam a fauna e a flora ao destruir seu habitat, comprometem rios e bacias hídricas e contribuem para o enfraquecimento do solo e a ocorrência de erosão. Além do mais, solos com pouca cobertura vegetal diminuem a infiltração da água, aumentando a ocorrência de eventos como enchente e inundações, causando graves transtornos à população humana.

\section{REFERÊNCIAS}

ABREU, Loyde Vieira de. Avaliação da escala de influência da vegetação no microclima por diferentes espécies arbóreas. Dissertação (Mestrado em Engenharia Civil) - Universidade Estadual de Campinas, Campinas, 2008. Disponível em: http:/ / repositorio.unicamp.br/bitstream/REPOSIP/257749/1/Abreu_LoydeVieirade_M. pdf. Acesso em: 27 ago. 2017.

AYOADE, J. O. Introdução à climatologia para os trópicos. $15^{a}$ edição. Rio de Janeiro: Bertrand Brasil, 2011. 
COLTRI, Priscila Pereira. Influência do uso e cobertura do solo no clima de Piracicaba, São Paulo: análise de séries históricas, ilhas de calor e técnicas de sensoriamento remoto. Dissertação (Mestrado em Agronomia) - Universidade de São Paulo, Piracicaba, 2006. Disponível em: http:/ / www.teses.usp.br/teses / disponiveis/11/11136/tde-25102006-123617/publico/PriscilaColtri.pdf. Acesso em: 27 ago. 2017.

CORREIA, Francis Wagner Silva et al. Balanço de umidade na Amazônia e sua sensibilidade às mudanças na cobertura vegetal. Ciência e Cultura, São Paulo, v. 59, n. 3, p. 39-43, 2007. Disponível em: http:/ / cienciaecultura.bvs.br/scielo.php?script=sci_ arttext\&pid=S0009-67252007000300016\&lng=en\&nrm=iso. Acesso em: 25 jul. 2017.

COSTA, Caio César Azevedo, et al. Produção de serapilheira na Caatinga da Floresta Nacional do Açu-RN. Revista Brasileira de Biociências, v. 5, n. S1, p. 246-248, 2007. Disponível em: http:/ / www.ufrgs.br/seerbio/ojs/index.php/rbb/article/ download/273/241. Acesso em: 18 ago. 2017.

MUNSELL COLOR. Munsell Soil color charts. Baltimore, 2000.

NATEL JUNIOR, Vilson Luiz Ferreira. A influência da vegetação sobre o clima urbano de Curitiba-PR: estudo de caso. 2015. Monografia (Especialização em Análise Ambiental) - Universidade Federal do Paraná, Curitiba, 2015. Disponível em: http:/ / www.acervodigital.ufpr.br/bitstream/handle/1884/40291/R\%20-\%20E\%20-\%20 VILSON\%20LUIZ\%20FERREIRA\%20NATEL\%20JUNIOR.pdf?sequence=1. Acesso em: 25 jul. 2017.

PEREIRA, A. R.; ANGELOCCI, L. R.; SENTELHAS, P. C. Agrometeorologia: fundamentos e aplicações práticas. Guaíba: Agropecuária, 2002.

SANTANA, José Augusto da Silva. Estrutura fitossociológica, produção de serapilheira e ciclagem de nutrientes em uma área de Caatinga no Seridó do Rio Grande do Norte. Tese (Dourado em Agronomia) - Universidade Federal da Paraíba, Areia, 2005. Disponível em: http:/ / tede.biblioteca.ufpb.br/bitstream/tede/8190/2/ arquivototal.pdf. Acesso: 18 ago. 2017.

SCHUHMANN, Maitê Luize. O contexto e os efeitos do PRONAF Mais Alimentos para os agricultores familiares do município de Teutônia-RS. 2012. Dissertação (Programa de Pós-graduação em Extensão Rural) - Universidade Federal de Santa Maria, Santa Maria, agosto de 2012. Disponível em: http:/ / www. reformaagrariaemdados.org.br/sites/default/files/2012\%20SCHUHMANN,\%20 MAITE\%20LUIZE.pdf Acesso em: 25 jul. 2012.

SOUTO, Patrícia Carneiro. Acumulação e decomposição da serapilheira e distribuição de organismos edáficos em área de Caatinga na Paraíba. Tese (Doutorado em Agronomia) -Universidade Federal da Paraíba, Areia, 2006. Disponível em: http:/ / bdtd.biblioteca.ufpb.br/bitstream/tede/8199/2/arquivototal.pdf. Acesso em: 18 ago. 2017. 
TEIXEIRA, Pedro Heringer Lisboa; LUCAS, Taiza de Pinho Barroso. A influência da vegetação em um microclima da cidade de Belo Horizonte, MG. Caderno de Geografia, v.24, n.42, 2014. Disponível em: http:/ / periodicos.pucminas.br/index. php/geografia/article/download/6623/6739. Acesso em: 18 ago. 2017.

TUCCI, Carlos Eduardo Morelli; CLARKE, Robin T. Impacto das mudanças da cobertura vegetal no escoamento: Revisão. Revista Brasileira de Recursos Hídricos, Porto Alegre - RS, v. 02, n.01, p. 135-152, 1997. Disponível em: http:/ / rhama.com. br/blog/wp-content/uploads /2016/12/impacto-das-mudan \%C3\%83\%C2\%A7ascobertura-vegetal-no-escoamento.pdf. Acesso em: 25 jul. 2017.

VITAL, Ana Rosa Tundis, et al. Produção de serapilheira e ciclagem de nutrientes de uma Floresta Estacional semidecidual em zona ripária. Revista Árvore, v. 28, n. 6, p. 793-800, 2004. Disponível em: http:/ / www.scielo.br/pdf/rarv/v28n6/23980.pdf. Acesso em: 17 ago. 2017.

WEBER, Simone Elisa. Colonização Germânica no Vale do Taquari: os colonos católicos de Santa Clara (século XIX). 2016. Monografia (Graduação em História) Centro Universitário UNIVATES, Lajeado, 28 nov. 2016. Disponível em: <http:/ /hdl. handle.net/10737/1551>. Acesso em: 25 jul. 2017.

WINDISCH, Paulo Gunter; STEFFENS, Cristiano. Diversidade e formas de vida das pteridófitas do Morro da Harmonia de Teutônia, RS, Brasil. Pesquisas. Botânica, v. 58, p. 375-382, 2007. Disponível em: http:/ / www.anchietano.unisinos.br/publicacoes / botanica/botanica58/artigo14.pdf. Acesso em: 25 jul. 2017.

YU, Chen; HIEN, Wong Nyuk. Thermal benefits of city parks. Energy and Buildings, v. 38, p. 105-120, 2006. Disponível em: http:/ / www.sciencedirect.com/science/ article/pii/S0378778805000794. Acesso em: 19 ago. 2017. 